\title{
THE EFFECT OF THERAPEUTIC MASSAGE IN PATIENTS WITH CHRONIC NECK PAIN
}

\author{
Denka Marinova \\ National Sports Academy „Vassil Levski”, Sofia, Bulgaria
}

\begin{abstract}
Chronic neck pain is having a considerable impact on quality of life and is a challenging condition to treat in clinical practice. The aim of this study is to assess the therapeutic methodology, which includes massage therapy with treatment of trigger points and stretching, in a combination with passive exercises, and its effect on patients with chronical neck pain. Objects: 52 patients with chronical neck pain, organized in two groups - experimental and control group. Methods: Twenty-six patients in the experimental group received ten therapeutic massages with exercise therapy. The patients in control group subjected to only control testing without undergoing a therapeutic massage course. For the study purposes twice were assessed the changes in the static and dynamic pain via modified Borg's static pain tests and Merle D'Aubigné dynamic pain test, and also the changes of cervical spine mobility. Results: At the end of the research, it was statistically ascertained that in case of experimental group patients there was a significant pain decrease at palpation and motions. At a maximum intensity of static pain at baseline of 7.35 ( \pm SD2.6), at the end of therapy it was 3.96 $( \pm S D 4.9)(p<0.001)$. At ten therapeutic massages, intensity of pain in movement was significantly reduced $-2.8,3$ $( \pm S D \leq 1.96)(p<0.001)$, while in control group that change was minimal. In experimental group was report improved neck range function ( $L R=56,3 \pm 2,4)(p \leq 0,001) ; R R=58,6 \pm 6,3$ ( $p \leq 0,001) ; R L F=33,3 \pm 3,6$ ( $p \leq 0,05) ; L L F=36,8 \pm 4,7$ ( $p \leq 0,01) ; F l=28,6 \pm 7,2 ; E x=27,9 \pm 3,7)$, at the end of the study. Conclusion: on the basis of the obtained results we found that the important for the functional condition of the neck area indexes, which determine the overall mobility (namely the range of motion), improved quantitatively and statistically significantly after the therapeutic massage course in an experimental group. This means that there is a normal correlation in the improvement of mobility indexes with the established neck pain reduction, which proves the objectivity of the observed changes under the influence of therapeutic massage.
\end{abstract}

Key words: massage therapy, neck pain, trigger point

\section{INTRODUCTION}

Pain is a subjective symptom generated by the nociceptive system as a result of tissue damage or neurological disturbance (Treede et al., 2006). Chronic neck pain (CNP) is a significant and topical medical issue (Vassilaki et al., 2014). CNP is the constant pain or strong discomfort in the neck area lasting for more than three months (Milanov, 2014). The study of this symptom is imposed by its prevalence and the new possibilities for medical treatment. The disease is observed among to $80 \%$ of the population but is less prevalent than that in the lumbar area of the spinal column (Romanoff et al, 2004). When monitoring patients with CNP over a period of one to five years, we find out that at least half of them report for constant or repeated problems in this area (Haldeman, Dagenais, 2008). A number of anatomic-physiological and topographic peculiarities of the neck area of the spinal column lead to its loading, proneness to damage, and compensatory possibilities (Grant, et al.,2002). The CNP sometimes is not well located; deteriorates upon movement and is accompanied by muscle hypertonia (Milanov, 2009).

In the last years therapeutic massage (TM) has been recommended as an additional and integrative medical treatment for alleviating different kinds of pain, including neck pain (Celenay, et al., 2016). $\mathrm{CNP}$ is the second leading reason for the use of complementary and alternative medicine (Barnes, Bloom, 2008). The influence of physiotherapy, acupuncture, massage and manual mobilizations on neck pain is traced in different publications (Furlan, et al., 2012; Sherman, et al., 2014; Goranova, 2018), but the best conservative therapy method is about to be determined. Therapeutic massage is a manual treatment combining different kinds of massage techniques with a relaxing, oxidation and vasodilation effects. Lots of surveys evaluate the efficiency of massage for CNP (Sherman, et al., 2009; Kostov, 2011; Topolska, et al., 2012). It is important to point out the need of regular treatment which includes TM with an emphasis on the normalization of the muscle tone of the neck, followed by passive 
movements close to functional activity.

The aim of this study is to assess the therapeutic influence of a therapeutic massage among patients with a chronic pain in the cervical area of the spinal column.

\section{METHODOLOGY}

The research was done over a 3-year period (20162018) at the physical medicine ward of the eighth diagnostic-consultancy center in Sofia. 52 patients with CNP were observed. The main criteria for inclusion in the research were: age between 20 and 65 years, presence of one-sided or two-sided pain in the neck (dating from not less than 6 months), a written informed agreement for participation in the research. Criteria for exclusion from the research: surgeries of discus hernia in the cervical area of the spinal column, surgeries of thyroid gland or shoulder joint within a year before the beginning of the research; weakened reflexes, indications for grave spinal pathology such as tumors, compression fractures, osteoporosis, Bekhterev's disease, neurological deficit in an upper limb and positive neurodynamics testing; unbearably acute constant neck pain not influenced by analgetics.

The patients who fulfilled the criteria were divided randomly into experimental group (EG) and control group (CG). The experimental group included 26 patients with mean age 38.16 years ( $\mathrm{SD} \pm 14.28$ ). They undertook a ten-day course with a treatment program including: a therapeutic massage, stretching, and passive exercises for neck. The control group consisted of 26 patients with mean age 39.5 $(\mathrm{SD} \pm 13.35)$ years. They were subjected to only control testing without undergoing a therapeutic massage course. When comparing the patients from the two groups we did not find any significant differences as regards age, gender, and duration of the disease.

The pain generated from the cervical area should be differentiated into static (palpatory) and spontaneous (in movement). In order to fulfill the aims of the research we traced (at the beginning and at the end of the treatment) the changes in the intensity of the static and dynamic neck pain with the modified scales of Borg's and Merle D'Aubigné. The Borg's scale assesses palpatory/static pain. It is 10-level scale (0-10 scores) for a subjective definition of the pain degree, where 0 is lack of pain sensitivity and 10 - acute, unbearable pain.
The research is done with palpation of cervical segment where the presence of pain upon pressure on muscles, structures and trigger points. The modified Merle d'Aubigné scale measures the intensity of dynamic pain - movement pain. The scale is of 7 levels (0-6) to define the pain degree in case of exercising different movements in the neck zone. The advantages of the above-mentioned scales are: both are easily applicable; both have good shortterm reproducibility and sensibility to therapeutic interventions; they are useful to assess effectivity of the applied therapy.

To make the changes in the neck function more objective, we studied the range of motion in the cervical segment with SFTR - methods - flexion, extension, lateral bends, rotations.

The aim of the applied massage course is maximum pain reduction and recovery of the function of the cervical region of the spinal column. Therapeutic massage is based on the following main principles: an individual approach suitable for the gravity of pain symptomatic, presence of additional diseases, age, and general condition of the patients; gradual increase in the force of massage impact both during the single treatment and over the whole massage course; appropriate selection and adaptation of the applied massage techniques; taking correct position during the procedure.

The treatment course included 10 massage procedures. They were held twice a week over a 5-week period. The massage procedure lasted for $30 \mathrm{~min}$ and were individually applied considered according to the patient's condition. The massage procedure included the main techniques of classic massage from sitting or lying position. During the massage procedure we treated established trigger points in the neck-thorax area with specific techniques of processing. The massage procedure finished with stretching and passive exercises of the neck region. All massage techniques were performed within the comfort zone. It was important that the patients should not experience strong pain both during the massage and afterwards.

\section{RESULTS}

The data obtained in this study was analyzed using SPSS version 21.0. To make comparisons between the pre- and post-researches for the two groups, Student's t-test for paired and unpaired sample was performed and a p-value less than 0.05 was consid- 
ered to indicate a statistically significant difference. sitiveness to pain with the modified scales of Borg's The results from the research of the subjective sen- and Merle d'Aubigne are presented in Table 1.

Table 1. Changes in the intensity of pain in the experimental and control groups during the study

\begin{tabular}{|c|c|c|c|}
\hline Pain assessment & Group & $\begin{array}{c}\text { Pre } \\
\mathrm{X}_{1} \pm \mathrm{SD}_{1}\end{array}$ & $\begin{array}{c}\text { Post } \\
\mathrm{X}_{2} \pm \mathrm{SD}_{2}\end{array}$ \\
\hline $\begin{array}{l}\text { Borg's scale for } \\
\text { of static pain }\end{array}$ & $\begin{array}{l}\text { EG CG } \\
\mathrm{p}\end{array}$ & \begin{tabular}{|l|}
$7.35 \pm 2.6$ \\
$7.53 \pm 4.2$ \\
0.718
\end{tabular} & \begin{tabular}{|l}
$3.96 \pm 4.9^{* * *}$ \\
$6.35 \pm 2.8$ \\
0.001
\end{tabular} \\
\hline $\begin{array}{l}\text { Merle d'Aubigné scale of dynamic } \\
\text { pain }\end{array}$ & $\begin{array}{l}\text { EG CG } \\
\mathrm{p}\end{array}$ & \begin{tabular}{|l|}
$5.38 \pm 7.3$ \\
$5.62 \pm 2.8$ \\
0.736
\end{tabular} & $\begin{array}{l}2.5 \pm 6.2 * * * \\
4.6 \pm 7.5 \\
0.001\end{array}$ \\
\hline
\end{tabular}

$X 1, X 2$ - mean values of the indexes for the two surveys; SD1,2 - standard deviations of the indexes for the two surveys; $E G$ - experimental group ( $n=26) ; C G$ - control group $(n=26)$; ${ }^{* *} p<0.001-$ significant differences in comparison to initial values determined with Student $t$-test for dependent and independent samples; P- significance of differences between the two groups

The changes having taken place as a result of the nical neck pain are laid down in Table 2 . conducted massage therapy to patients with chro-

Table 2. Changes in the average values and standard deviations of cervical range motion level measured at the beginning and the end of treatment with SFTR.

\begin{tabular}{|c|c|c|c|}
\hline Cervical range motion & Participants & $\begin{array}{c}\text { Pre } \\
\mathbf{X}_{1} \pm \mathrm{SD}_{1}\end{array}$ & $\begin{array}{c}\text { Post } \\
\mathrm{X}_{2} \pm \mathrm{SD}_{2}\end{array}$ \\
\hline Left rotation & $\begin{array}{l}\text { EG } \\
\mathrm{CG} \\
\mathrm{p}\end{array}$ & \begin{tabular}{|l|}
$37,0 \pm 5,8$ \\
$37,3 \pm 2,5$ \\
0.528
\end{tabular} & \begin{tabular}{|l}
$56,3 \pm 2,4 * * *$ \\
$39,8 \pm 4,1$ \\
0,001
\end{tabular} \\
\hline Right rotation & $\begin{array}{l}\text { EG } \\
\text { CG } \\
p\end{array}$ & \begin{tabular}{|l}
$37,9 \pm 1,6$ \\
$38,1 \pm 4,7$ \\
0.825
\end{tabular} & $\begin{array}{l}58,6 \pm 6,3 * * * \\
35,9 \pm 5,1 \\
0,05\end{array}$ \\
\hline Right lateral flexion & \begin{tabular}{|l} 
EG \\
$\mathrm{CG}$ \\
$\mathrm{p}$ \\
\end{tabular} & \begin{tabular}{|l|}
$23,2 \pm 8,4$ \\
$23,7 \pm 6,1$ \\
0.935 \\
\end{tabular} & \begin{tabular}{|l|}
$33,3 \pm 3,6$ \\
$24,5 \pm 7,2$ \\
0,01 \\
\end{tabular} \\
\hline Left lateral flexion & $\begin{array}{l}\text { EG } \\
\text { CG } \\
p\end{array}$ & \begin{tabular}{|l|}
$24,3 \pm 3,9$ \\
$24,5 \pm 3,9$ \\
0.707
\end{tabular} & $\begin{array}{l}36,8 \pm 4,7 * * * \\
24,8 \pm 5,7 \\
0,02\end{array}$ \\
\hline Flexion & \begin{tabular}{|l} 
EG \\
CG \\
$\mathrm{p}$ \\
\end{tabular} & \begin{tabular}{|l|}
$22,7 \pm 5,9$ \\
$22,1 \pm 3,4$ \\
0.941 \\
\end{tabular} & \begin{tabular}{|l|}
$28,6 \pm 7,2$ \\
$23,6 \pm 6,5$ \\
0.438 \\
\end{tabular} \\
\hline Extension & \begin{tabular}{|l} 
EG \\
$\mathrm{CG}$ \\
$\mathrm{p}$
\end{tabular} & \begin{tabular}{|l|}
$24,2 \pm 7,3$ \\
$23,8 \pm 6,5$ \\
0.438 \\
\end{tabular} & \begin{tabular}{|l}
$27,9 \pm 3,7$ \\
$24,9 \pm 5,2$ \\
0.069
\end{tabular} \\
\hline
\end{tabular}

$\mathrm{X}_{1} \mathrm{X}_{2}$. mean values of the indexes for the two surveys; $S D_{1,2}$ - standard deviations of the indexes for the two surveys; ${ }^{* *} p<0.001$ - significant differences in comparison to initial values determined with Student $t$-test for dependent and independent samples; P- significance of differences between the two groups

\section{DISCUSSION}

Pain is one of the leading criteria for assessment of the efficiency of the applied massage therapy. In the initial testing a presence of heavy pain was established in the two groups both in palpation and in movement. The follow-up of the pain static shows the existence of heavy pain at the beginning of the therapy, with a tendency to decrease after starting the treatment for EG. On comparing the results at the beginning and the end of the research, statis- 
tically credible difference in the average values of results is identified. At a maximum intensity of static pain at baseline of $7.35( \pm$ SD 2.6), at the end of therapy it was $3.96( \pm \mathrm{SD} 4.9)(\mathrm{p}<0.001)$ for $\mathrm{EG}$. The average value reached $3.38( \pm \mathrm{SD} \leq 1.25)$. At the end of the treatment course, as a result of the ministered therapy, statistically significant decrease in the pain with neck movements is ascertained at EG. When comparing the mean values along modified Merle d'Aubigné scale for assessment of dynamic pain, we found that the intensity of pain in movement was significantly reduced $-2.83( \pm \mathrm{SD} \leq 1.96)(\mathrm{p}<0.001)$ in EG, while in CG that change was minimal. The positive effect of massage reflected the efficiency of the applied massage methods and its complex influence as regards neck pain. These data are confirmed in other literary sources which show that pain is a symptom subject to reduction under the influence of healing massage (Back, 2009; Jurch, 2010; Goranova, 2018).

The observed improvement in functional results for the EG is related to the application of massage techniques combined with exercises for stretching and passive neck. Their combination with treating triggering points in the muscles in the neck area and shoulders coincides with the recommendations of Gemmell, et al., (2008). We believe that the purposeful individual influence on the damaged structures in the neck area through adequately selected massage techniques leads to a muscle relaxation and decreased tone of the strong muscles. This is the way for recovery of the muscle dysfunction and making the neck range of motion in normal. In our opinion, the changes in the neck range motion are beneficial influence in the results of the patients from the EG. They were mostly due to the effect from the individual approach to each patient. An important moment in the massage therapy is achieving a relatively constant result in patients' condition. The need of a prolonged therapeutic massage application was confirmed in our research by the lower results in the flexion and extension of the neck in EG at the end of the researched period. In the CG, which did not undergo a massage therapy, the observed detention of the researched indexes showed the relation between the MT and chronic pain. In a meta-analysis, Cheng et al. (2014) showed that TM has better immediate effects in chronic relief of neck pain than other physical therapies, but there is no valid evidence that TM improves cervical dysfunction. The analysis of the neck range motions results identifies a large difference in evaluations in the end of therapy. On the course of treatment, a better motor function is established, which is ascribed to the pain decrease and the improvement of the functional condition of the neck. The average value at the beginning is $26.7 \pm 3.9( \pm$ SD 0.74$)$, while at the end of the therapy, it is $35.4 \pm 7.2( \pm$ SD 0.86) $(\mathrm{p}<0.001)$ for EG. Regular use of massage therapy can not only prevent worsening neck pain but also act as a prophylaxis to the development of complications (Sherman, et al., 2009). This is achieved through the improvement of both physical and mental health (Atanasov, 2012).

\section{CONCLUSION}

The researched indexes showed that the treatment course had improved the condition of the patients from the EC, but as regards CNP the improvement was the most distinctive and statistically significant. On the basis of the obtained results we found that the important for the functional condition of the neck area indexes, which determine the overall mobility (namely the range of motion), improved quantitatively and statistically significantly after the therapeutic massage course. This means that there is a normal correlation in the improvement of mobility indexes with the established neck pain reduction, which proves the objectivity and regularity of the observed changes under the influence of therapeutic massage.

\section{REFERENSES}

Atanasov, S. (2012). Biomehanichni osobenosti na tzervikalnia dyal na grabnachnia stalb. Nauchni trudove na Rusenski universitet . Ruse, Vol. 51, Series 8.1, pp. 18-20. Back, M. (2010). Theory and Practice of Therapeutic Massage. Milady, USA, 5th ed., April 23, pp. 545-601.

Barnes, P., Bloom, B. (2008). Complementary and alternative medicine use among adults and children: United states, 2007. National Health Statistics Reports, 12, December, pp. 1-23.

Celanay, S., Kaya, D., Akbayrak, T. (2016). Cervical and scapulothoracic stabilization exercises with and without connective tissue massage for chronic mechanical neck pain: A prospective, randomised controlled trial. available at: https://www.ncbi.nlm.nih.gov/ pubmed/26211422/ (accessed 15 Juny 2017).

Cheng, Y., Huang, G. (2014). Efficacy of Massage Therapy on Pain and Dysfunction in Patients with Neck Pain: A Systematic Review and Meta-Analysis. available at: https://www.hindawi.com/journals/ecam/2014/204360/ 
(accessed 28 Mach 2018).

Furlan, D., Yazdi, F., Tsertsvadze, A., Gross, A., Van Tulder, M., Santaguida, L., Gagnier, J., Ammaendoli, C., Dryde, T., Doucette, S., Skidmore, B., Daniel, R., Ostermann, T., Tsouros, S. (2012). A systematic review and meta-analysis of efficacy, cost-effectiveness, and safety of selected complementary and alternative medicine for neck and low-back pain. available at: https://www.ncbi.nlm.nih.gov/pubmed/22203884/ (accessed 17 May 2019).

Gemmell, H., Miller, P., Nordstrom, H. (2008). Immediate effect of ischaemic compression and trigger point pressure release on neck pain and upper trapezius trigger points: a randomised controlled trial. Clinical Chiropractic, vol.11, no.1, pp. 30-36.

Goranova, Z. (2018a). Bolkata v lumbosakralnia region. Tradizionnata kitaiska medizina $v$ obrazovanieto i medizinskata proktika, NSA PRES, Sofia, pp. 184-194.

Goranova, Z. (2018b). Bi-sindrom v tradizionna kitaiska medizina. Tradizionnata kitaiska medizina v obrazovanieto $i$ medizinskata proktika, NSA PRES, Sofia, pp. 184194.

Grant, R., Bogduk, N., Taylor, J., Twomey, L., Magarey, M. (2002). Physical Therapy of the cervical and thoracic spine. Churchill Livingstone, London, pp. 26-32.

Haldeman, S, Dagenais, S. (2008). What have we learned about the evidence-informed management of chronic low back pain? J Spine, Elsevier, January, Vol 8, Issue 1, pp 266-277.

Jurch, S. (2009). Clinical massage therapy. McGraw-Hill, New York, pp. 95-111.

Kostov, K. (2011). Izsledvane varhu znachrnieto na stimuliranata shiyno-mozachna kinestezia $\mathrm{v}$ prozedurite po kineziterapia pri bolka v tzervikalnia diyl na grabnachnia stalb. Godishnik na Sofiiskia universitet "Sv. Kliment Ohridski", Sofia, pp. 73-82.

Milanov, I. (2009). Bolkata v nevrologichnata praktika. Medizina i fizkultura, Sofia, pp. 17-20.
Milanov, I. (2014). Savremenni sxvashtania za bolkata. Cephalgia, Vol. 16, № 2, pp. 31-40.

Romanoff, E., Gilbert, L., Warfield, A. (2004). Neck pain. In: Principle and practice of pain medicine. Warfield, C.A. Bajwa, Z.H., eds. McGraw-Hill. New York, 260-272. Sherman, K., Cherkin, D., Hawkes, R., Miglioretti, D., Deyo, R. (2009). Randomized trial of therapeutic massage for chronic neck pain. available at: https:// www.ncbi.nlm.nih.gov/pubmed/19333174/ (accessed 28 October 2017).

Sherman, K., Cook, A., Wellman, R., Hawkes, R., Kahn, J.,Deyo, R.,Cherkin, D. (2014). Five-Week Outcomes From a Dosing Trial of Therapeutic Massage for Chronic Neck Pain. available at: https://www.ncbi.nlm.nih. gov/pmc/articles/PMC3948757/ (accessed 14 December 2018).

Tasheva, R. (2013). Nervno muskulno-skeletno izsledvane na tzervikalen i na tzervikotorakalen dyal. Medizina i sport, br. 1-2, pp 22-26.

Topolska, M., Chrzan, S., Sapuła, R., Kowerski, M., Sobon, M., Marczewski, K. (2012). Evaluation of the effectiveness of therapeutic massage in patients with neck pain. Ortopedia Traumatologia Rehabilitacja, vol. 14, pp. 115-124.

Treede, R., Cervero, F., Jensen, T., (2006). Pain and hyperalgesia: definition and theories. In: Handbook of clinical neurology. Pain, Elsevier, Amsterdam, B1, pp. 3-10.

Vassilaki, M, Hurwitz, EL. (2014). Perspectives on pain in the low back and neck: global burden, epidemiology, and management. available at: https://www.ncbi. nlm.nih.gov/pubmed/24765562/ (accessed 27 February 2017).

\section{Correspondence autor:}

Denka Marinova

National Sports Academy „Vassil Levski” Department "Physiotherapy" Sofia, Bulgaria E-mail: denka_marinova@abv.bg 